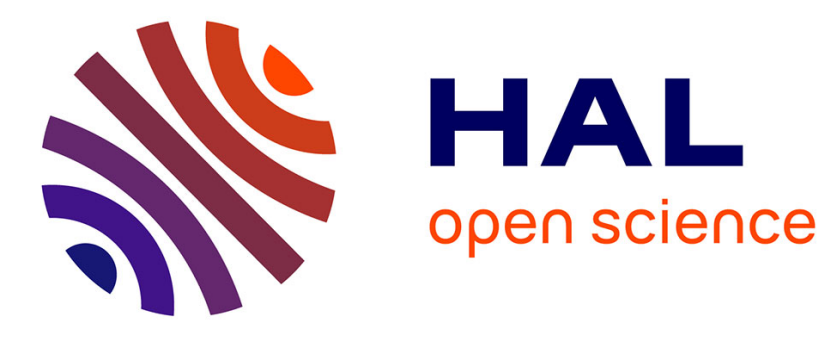

\title{
Blood fibrocytes are associated with severity and prognosis in COVID-19 pneumonia
}

Mada Ghanem, Méline Homps-Legrand, Marc Garnier, Lise Morer, Tiphaine Goletto, Justine Frija-Masson, Paul-Henri Wicky, Pierre Jaquet, Catherine Bancal, Margarita Hurtado-Nedelec, et al.

\section{To cite this version:}

Mada Ghanem, Méline Homps-Legrand, Marc Garnier, Lise Morer, Tiphaine Goletto, et al.. Blood fibrocytes are associated with severity and prognosis in COVID-19 pneumonia. American Journal of Physiology - Lung Cellular and Molecular Physiology, 2021, 321 (5), pp.L847 - L858. 10.1152/ajplung.00105.2021 . hal-03416731

\section{HAL Id: hal-03416731 \\ https: / hal.sorbonne-universite.fr/hal-03416731}

Submitted on 5 Nov 2021

HAL is a multi-disciplinary open access archive for the deposit and dissemination of scientific research documents, whether they are published or not. The documents may come from teaching and research institutions in France or abroad, or from public or private research centers.
L'archive ouverte pluridisciplinaire HAL, est destinée au dépôt et à la diffusion de documents scientifiques de niveau recherche, publiés ou non, émanant des établissements d'enseignement et de recherche français ou étrangers, des laboratoires publics ou privés. 


\title{
RESEARCH ARTICLE
}

The Pathophysiology of COVID-19 and SARS-CoV-2 Infection

\section{Blood fibrocytes are associated with severity and prognosis in COVID-19 pneumonia}

\author{
(1) Mada Ghanem, ${ }^{1,2 *}$ Méline Homps-Legrand, ${ }^{1 *}$ Marc Garnier, ${ }^{1,3}$ Lise Morer, ${ }^{2}$ Tiphaine Goletto, ${ }^{2}$ \\ (D) Justine Frija-Masson, ${ }^{4}$ (D) Paul-Henri Wicky, ${ }^{5}$ Pierre Jaquet, ${ }^{5}$ Catherine Bancal, ${ }^{4}$ \\ Margarita Hurtado-Nedelec, ${ }^{6}$ (D) Luc de Chaisemartin,, ${ }^{7}$ Madeleine Jaillet, ${ }^{1}$ Arnaud Mailleux, ${ }^{1}$ \\ Christophe Quesnel, ${ }^{1,3}$ Nicolas Poté, ${ }^{1,8}$ Marie-Pierre Debray, ${ }^{1,9}$ Etienne de Montmollin, 5 \\ Catherine Neukirch, ${ }^{1,2}$ Raphael Borie, ${ }^{1,2}$ Camille Taillé, ${ }^{1,2}$ (D) Bruno Crestani, ${ }^{1,2}$ and the French COVID Cohort \\ Study Group \\ ${ }^{1}$ Laboratoire d'excellence INFLAMEX, Université de Paris, Inserm, U1152, Paris, France; ${ }^{2}$ APHP, Service de Pneumologie A, Centre \\ de référence des Maladies Pulmonaires Rares, FHU APOLLO, Hôpital Bichat, Paris, France; ${ }^{3}$ Sorbonne Université, APHP, DMU \\ DREAM, Service d'Anesthésie-Réanimation et Médecine Périopératoire, Hôpital Tenon, Paris, France; ${ }^{4} A P H P$, Laboratoire \\ d'Explorations Fonctionnelles, Hôpital Bichat, Paris, France; ${ }^{5}$ APHP, Service de Réanimation Médicale et Infectieuse, Hôpital \\ Bichat, Paris, France; ${ }^{6}$ Université de Paris, APHP, Laboratoire d'immunologie, Hôpital Bichat, Inserm, Paris, France; \\ ${ }^{7}$ Université Paris-Sud, Université Paris-Saclay, APHP, Laboratoire d'immunologie, Hôpital Bichat, Paris, France, Inserm, \\ Châtenay-Malabry, France; ${ }^{8}$ APHP, Service d'Anatomie et Cytologie pathologique, Hôpital Bichat, Paris, France; and ${ }^{9}$ APHP, \\ Service de Radiologie, Hôpital Bichat, Paris, France
}

\begin{abstract}
Increased blood fibrocytes are associated with a poor prognosis in fibrotic lung diseases. We aimed to determine whether the percentage of circulating fibrocytes could be predictive of severity and prognosis during coronavirus disease 2019 (COVID-19) pneumonia. Blood fibrocytes were quantified by flow cytometry as CD45 ${ }^{+} / \mathrm{CD}_{1} 5^{-} / \mathrm{CD} 34^{+} /$collagen $^{-1^{+}}$cells in patients hospitalized for COVID-19 pneumonia. In a subgroup of patients admitted in an intensive care unit (ICU), fibrocytes were quantified in blood and bronchoalveolar lavage (BAL). Serum amyloid P (SAP), transforming growth factor- $\beta 1$ (TGF- $\beta 1$ ), CXCL12, CCL2, and FGF2 concentrations were measured. We included 57 patients in the hospitalized group (median age $=59$ yr [23-87]) and 16 individuals as healthy controls. The median percentage of circulating fibrocytes was higher in the patients compared with the controls (3.6\% [0.2-9.2] vs. 2.1\% [0.9-5.1], $P=0.04$ ). Blood fibrocyte count was lower in the six patients who died compared with the survivors (1.6\% [0.2-4.4] vs. 3.7\% [0.6-9.2], $P=0.02$ ). Initial fibrocyte count was higher in patients showing a complete lung computed tomography (CT) resolution at 3 mo. Circulating fibrocyte count was decreased in the ICU group (0.8\% [0.1-2.0]), whereas BAL fibrocyte count was $6.7 \%$ (2.2-15.4). Serum SAP and TGF- $\beta 1$ concentrations were increased in hospitalized patients. SAP was also increased in ICU patients. CXCL12 and CCL2 were increased in ICU patients and negatively correlated with circulating fibrocyte count. We conclude that circulating fibrocytes were increased in patients hospitalized for COVID-19 pneumonia, and a lower fibrocyte count was associated with an increased risk of death and a slower resolution of lung CT opacities.
\end{abstract}

COVID-19 pneumonia; fibrocyte; prognosis

\section{INTRODUCTION}

Coronavirus disease 2019 (COVID-19) pneumonia is caused by a new $\beta$-coronavirus, the severe acute respiratory syndrome coronavirus 2 (SARS-CoV-2). Severe cases are frequent and concern $15 \%-20 \%$ of hospitalized patients, who present with severe pneumonia or even acute respiratory distress syndrome (ARDS) (1). Respiratory failure is responsible for up to
$70 \%$ of deaths due to COVID-19 (2). Histologically, data from autopsies attest that COVID-19 severe pneumonia is characterized by extensive diffuse alveolar damage, with organizing pneumonia $(3,4)$. In more advanced disease, fibroblast proliferation with thickened alveolar septa suggesting a fibrotic process has been reported $(2,5-7)$.

To date, several clinical risk factors for an unfavorable outcome have been reported, including genetic background;

* M. Ghanem and M. Homps-Legrand contributed equally to this work.

Correspondence: B. Crestani (bruno.crestani@aphp.fr).

Submitted 5 March 2021 / Revised 26 August 2021 / Accepted 27 August 2021 
older age; male gender; individuals of black, Asian, and minority ethnicity; and comorbidities such as obesity, hypertension, diabetes, or chronic respiratory diseases $(8,9)$. Biological markers such as C-reactive protein (CRP), lactate dehydrogenase (LDH), autoantibodies against interferon- $\alpha$ and interferon- $\omega$, or lymphocyte subpopulations could also be linked to prognosis (10). Proinflammatory monocytederived macrophages have been described to be abundant in the bronchoalveolar lavage fluid (BALF) from patients with severe COVID-19, compared with moderate cases, who mainly showed abundant CD8 ${ }^{+} \mathrm{T}$ cells (11). Moreover, a recent study using single-cell RNA sequencing confirmed that monocytes were increased in BALF of patients with COVID-19 (12). This could suggest that the recruitment of circulating cells into the alveoli may participate in lung injury.

Fibrocytes are circulating mesenchymal cell precursors derived from the bone marrow, implicated in the repair process after a tissue injury. They are derived from a common monocyte lineage (13) and are suspected to be one of the cell sources of myofibroblasts $(14,15)$. Fibrocytes express the stem cell marker CD34, the pan-hematopoietic marker CD45, and monocyte markers (CD12 and CD11) and produce extracellular matrix components (collagen-I and collagenIII, among others) (16). Fibrocytes are involved in acute and chronic lung diseases $(16,17)$. Alveolar fibrocytes may originate from the recruitment of circulating fibrocytes to the lung mainly through the CXCR4-CXCL12 axis and from local differentiation of monocytes in alveolar spaces, which is promoted by profibrotic cytokines [IL-4, IL-13, transforming growth factor- $\beta$ (TGF- $\beta 1$ )] and inhibited by serum amyloid $\mathrm{P}$ (SAP) component, interferon- $\gamma$, and IL-12 $(18,19)$. In ARDS, increased blood fibrocyte counts are associated with increased mortality $(20,21)$. Fibrocytes accumulate in the alveolar environment of patients with acute lung injury or ARDS; a high fibrocyte count in BALF being a prognostic marker of unfavorable ARDS course (22). Circulating fibrocyte counts are also increased in patients with idiopathic pulmonary fibrosis (IPF), a prototypical fibrotic lung disorder. The percentage of circulating fibrocytes correlates with IPF progression and independently predicts mortality (23). Finally, fibrocytes are detected in the lung compartment of patients with IPF, both in BALF and lung tissue $(24,25)$.

Whether fibrocytes could be involved in COVID-19 pneumonia and predict severity and long-term resolution of acute radiological abnormalities is unknown. We hypothesized that circulating fibrocytes could be a valuable biomarker during COVID-19 pneumonia. We aimed to determine the involvement of fibrocytes during COVID-19 pneumonia and to determine if fibrocytes could be associated with prognosis.

\section{METHODS}

\section{Patient Recruitment}

All the adult patients admitted to the Pneumology Department of Bichat University Hospital (Paris, France) for a case of SARS-CoV-2 pneumonia between March 20 and April 21, 2020, who agreed to participate in the French COVID cohort (clinicaltrials.gov NCT04262921; approval of the ethics committee "CPP Ile-de-France VI," No. 2020-
A00256-33) were included in the study and constituted the hospitalized patients group. COVID-19 pneumonia was confirmed by a positive SARS-CoV-2 RT-PCR performed on a nasopharyngeal swab in all patients. A second group of patients with severe SARS-CoV-2 pneumonia admitted to the intensive care unit (ICU) due to mechanical ventilation or high-flow oxygen therapy requirement was also included (ICU patients group). Those ICU patients were also part of the French COVID cohort.

All patients underwent a chest computed tomography (CT) scan on admission to assess the pulmonary damages related to SARS-CoV-2 infection, defined by bilateral ground glass opacities or alveolar condensation. All CT scans were reviewed by one expert radiologist blinded to patients' course, who rated the extent of COVID-19 damages as representing $<25 \%, 25 \%-50 \%, 50 \%-75 \%$, or $>75 \%$ of total lung parenchyma (26). As part of the French COVID cohort, survivors underwent a second chest CT scan 3 mo after admission to assess the persistence of lung lesions.

A group of healthy volunteers ("controls"), who were ageand sex-matched with patients from the hospitalized group $( \pm 10 \mathrm{yr})$, were recruited as part of another study entitled "Evaluation of $\mathrm{CD}_{16}{ }^{+}$circulating monocyte differentiation into fibrocytes during acute lung injury" (Institutional Review Board Paris Nord Approval No. 11-023).

Written information was given, and informed consent was obtained from controls and patients or next of kin.

\section{Biological Samples}

For patients and controls, 5-mL blood samples were collected in Cyto-Chex blood collection tubes (Streck, Omaha, $\mathrm{NE}$ ) and stored at $4^{\circ} \mathrm{C}$ until FACS analysis. Serum samples were taken on the same day and stored at $-80^{\circ} \mathrm{C}$ until use. All patients routinely underwent a blood test at the time of sampling, including a hemogram and determination of serum C-reactive protein, ferritin, lactate dehydrogenase, and D-dimer.

BALF was obtained simultaneously with blood samples from ventilated patients. Bronchoalveolar lavage (BAL) was performed with $5 \times 20 \mathrm{~mL}$ of sterile $0.9 \%$ saline solution under fiberoptic control, as previously described, to assess the microbiological diagnosis of suspected ventilator-associated pneumonia (27). BALF samples were stored at $4^{\circ} \mathrm{C}$ in Cyto-Chex tubes until FACS analysis. When possible, blood samples were repeated on day 7 and 3 mo after admission for fibrocyte analysis.

\section{Fibrocyte Count by Flow Cytometry}

Fibrocytes (defined as $\mathrm{CD}_{4} 5^{+} / \mathrm{CD} 15^{-} / \mathrm{CD} 34^{+} / \mathrm{Coll}_{-} \mathrm{I}^{+}$ cells) were analyzed in blood and BALF using flow cytometry as previously described $(22,27)$. Briefly, white cell pellet obtained after red blood cell lysis (for blood) and cell pellet obtained after BALF centrifugation (for BAL) were resuspended in $100 \mu \mathrm{L}$ of PBS and incubated with CD45APC (BD Biosciences, Franklin Lakes, NJ), CD34-PE.Cy7 (BD Biosciences), and CD15-PE (BD Biosciences) antibodies for $15 \mathrm{~min}$ at $4{ }^{\circ} \mathrm{C}$. Then, cells were fixed and permeabilized with Cytofix/Cytoperm, washed with perm/wash buffer (Cytofix/Cytoperm Kit, BD Biosciences), and stained with collagen I-FITC conjugated antibody (Millipore, 
Burlington, MA) or IgG1k control isotype for $30 \mathrm{~min}$ at $4{ }^{\circ} \mathrm{C}$. Stained cells were measured with a flow cytometer (BD FACSCanto II, BD Biosciences), and data were analyzed with FlowJo software version 10.6.2. Fibrocyte count was expressed as a percentage of the whole population of living mononuclear leukocytes. The gating strategy is described in Fig. 1.

\section{Serum Amyloid P Component Quantification}

Serum SAP concentration was determined with a commercial human SAP ELISA kit as previously described (APCS Human ELISA Kit; Abcam, Cambridge, UK) (27). Serum samples were 1/25,000 diluted before ELISA.

\section{CXCL12, CCL2, FGF2, and TGF- $\beta 1$ Quantification}

CXCL12, CCL2, and FGF2 concentration in serum was determined by using the ProcartaPlex Human 10-plex Kit, and TGF- $\beta 1$ concentration in serum was determined by using the ProcartaPlex Human TGF- $\beta 1$ Simplex Kit (Thermo Fisher Scientific, Waltham, MA). Before measuring plasma TGF- $\beta 1$, the bioactive form of TGF- $\beta 1$ was generated by incubating the plasma with $1 \mathrm{~N} \mathrm{HCl}$ followed by neutralization with $1.2 \mathrm{~N} \mathrm{NaOH}$ according to the manufacturer's instructions.
All cytokines were measured using the Luminex MAGPIX instrument and quantified using the XPONENT analysis software (Luminex Corporation, Austin, TX).

\section{Multiplex Immunofluorescence Staining and Confocal Imaging for Fibrocyte Detection in Lung Samples}

Immunofluorescence staining was performed on human lung paraffin sections obtained from two patients with COVID-19. Human lung tissue sections were deparaffinized and blocked for $1 \mathrm{~h}$ in $4 \%$ BSA-PBS and $2 \%$ horse serum after 10 min in peroxidase blocking solution (Dako, Santa Clara, CA). Lung sections were first stained with CD45 antibody (dilution 1:100) (ZRB1180, Sigma-Aldrich, St. Louis, MO) overnight at $4^{\circ} \mathrm{C}$ followed by a poly-horseradish peroxidase goat anti-rabbit secondary antibody (Tyramide SuperBoost Kit, B40944, Invitrogen, Waltham, MA) amplified with Alexa Fluor 488 TSA dye (Tyramide SuperBoost Kit, B40941, Invitrogen). Sections were then incubated with citrate retrieval buffer. Sections were then stained with vimentin antibody (dilution 1:500) (ab92547, Abcam, Cambridge, UK) overnight at $4{ }^{\circ} \mathrm{C}$ and then followed by donkey anti-rabbit polyclonal secondary antibody conjugated with Alexa Fluor 568 (dilution 1:800) (A10042, Life Technologies, Carlsbad, CA). Quenching was performed to reduce autofluorescence

A

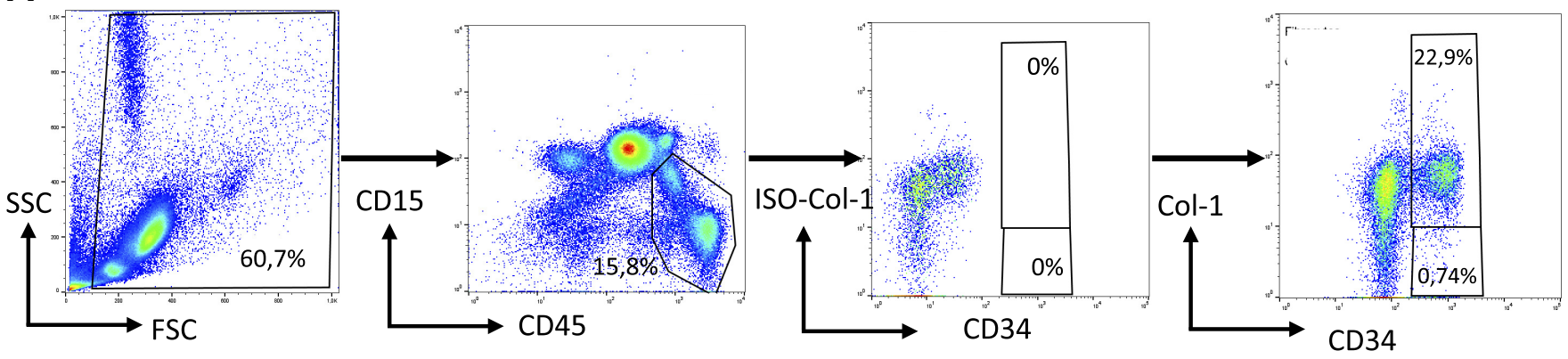

B

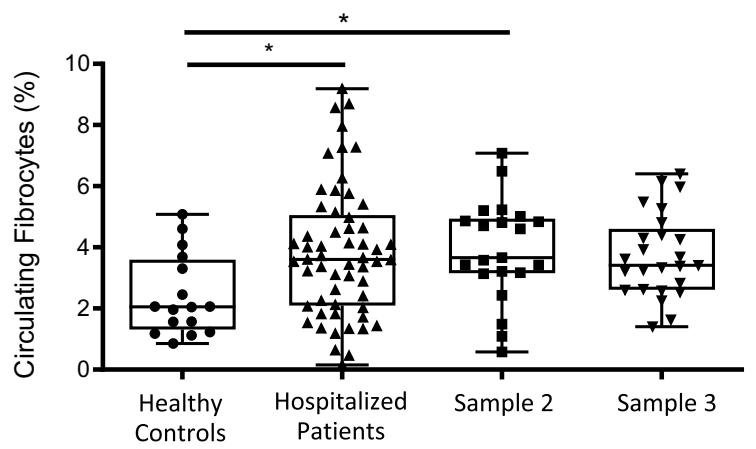

C

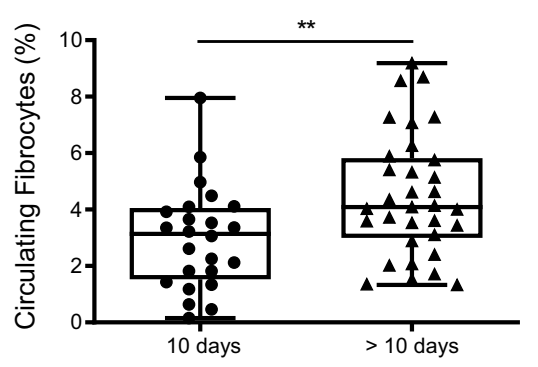

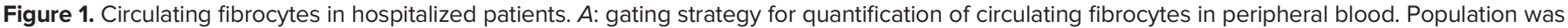

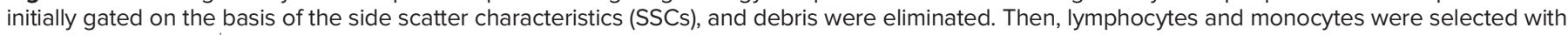

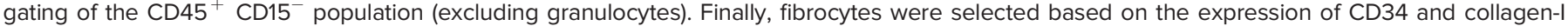

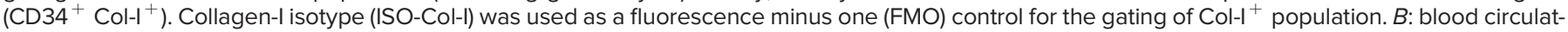

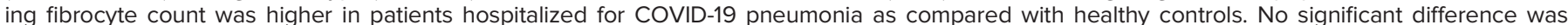

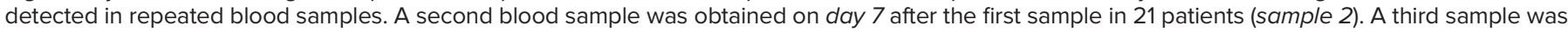

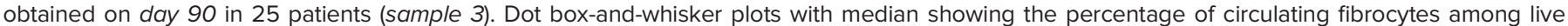

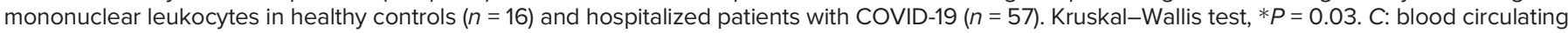

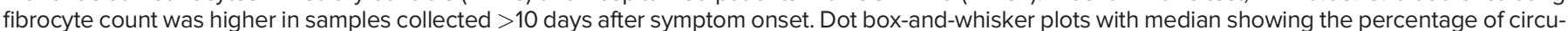

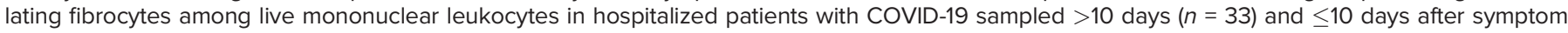
onset $(n=24)$. Mann-Whitney $U$ test, $* * P \leq 0.01$. 
Table 1. Summary of demographic and clinical data of the study subjects

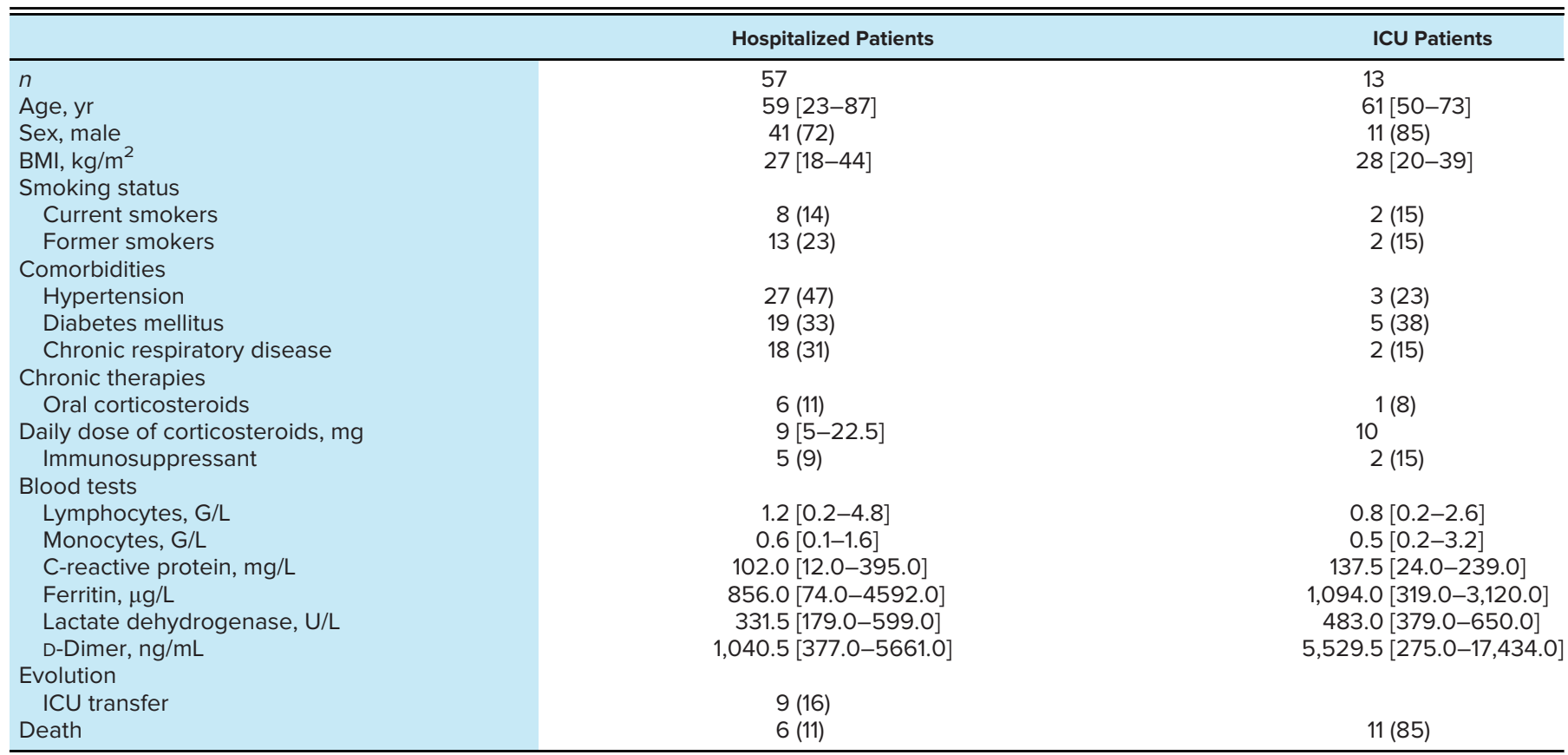

Values are median [range] or $n(\%)$.

(Vector TrueVIEW, SP-8400, Vector Laboratories Inc.). Lung sections were stained with DAPI for nucleus visualization (Vectashield Vibrance, H-1800, Vector Laboratories Inc.). Images were obtained using a Leica SP8 confocal microscope (original magnification $=\times 63)($ Leica Microsystems, Buffalo Grove, IL).

\section{Statistical Analysis}

Statistical analysis was performed with GraphPad Prism 6 (GraphPad Software, San Diego, CA). Data are presented as dot box-and-whisker plots and expressed as median [range]. Comparisons between two groups were assessed using the nonparametric Mann-Whitney $U$ test. Comparisons between multiple groups were assessed using the Kruskal-Wallis test, followed by Dunn's multiple-comparison test. When available, comparisons between changes in fibrocyte levels between two timepoints for the same patients were assessed using the Wilcoxon signed-rank test. Correlations were performed using the Spearman rank-order correlation coefficient. $P$ value $<0.05$ was considered as statistically significant.

\section{RESULTS}

\section{Patient Demographics}

A total of 57 patients ( 42 men and 15 women), with a median age of 59 [23-87] yr, were included in the hospitalized patients group. Their main clinical, demographic, and biological characteristics are listed in Table 1. The delay between the onset of symptoms and the first blood sample was 11 (4-31) days, whereas the delay between hospital admission and the first blood sample was 2 (0-11) days. During the hospitalization, nine of 57 patients were transferred to the ICU and four required invasive mechanical ventilation. Six patients (11\% of the hospitalized patients group) died, 6.5 (5-18) days after admission. Death was related to COVID-19 pneumonia progression in all six patients.

Thirteen patients [11 men and 2 women; median age $=61$ [50-73] yr] were included in the ICU patients group. The delay between the onset of symptoms and the first blood sample was 28 [6-41] days. Nine ICU patients (69\%) died during hospitalization.

\section{Circulating Fibrocytes in Hospitalized Patients}

Circulating fibrocyte count was increased in hospitalized patients, compared with healthy sex- and age-matched

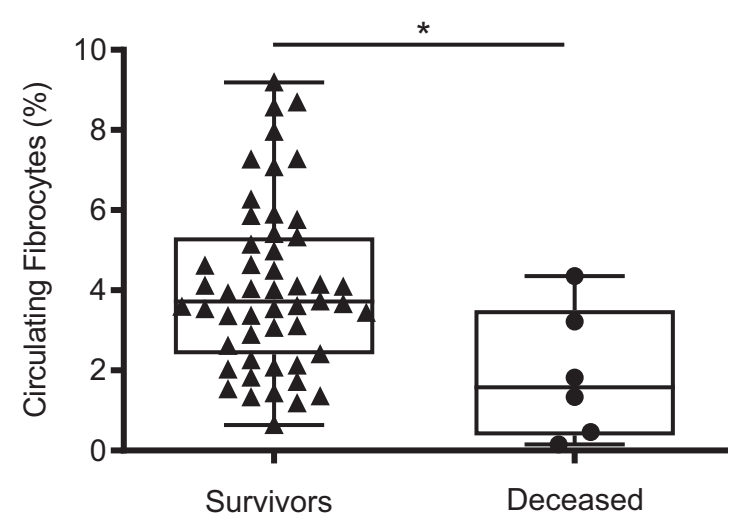

Figure 2. Blood fibrocyte count was decreased in patients who died during hospitalization as compared with survivors. Dot box-and-whisker plots with median showing the percentage of circulating fibrocytes among live mononuclear leukocytes in survivors $(n=51)$ and in patients who died $(n=$ 6). Mann-Whitney $U$ test, ${ }^{*} P \leq 0.05$. 
Table 2. Circulating fibrocyte count according to clinical risk factors for an unfavorable outcome in patients with COVID-19 pneumonia

\begin{tabular}{lcc}
\hline \hline & Circulating Fibrocytes, \% & P Value \\
\hline Sex & $3.5[0.2-8.69]$ & \\
$\quad$ Male & $3.8[0.5-9.2]$ & 0.7 \\
Female & & \\
Age, $y r$ & $3.6[0.6-9.2]$ & 0.8 \\
$\quad<60$ & $3.6[0.2-8.0]$ & \\
$\geq 60$ & $4.2[0.2-8.6]$ & 0.4 \\
$\mathrm{BMl}, \mathrm{kg} / \mathrm{m}^{2}$ & $3.5[1.3-9.2]$ & \\
$<25$ & $2.9[0.6-5.0]$ & \\
$25-30$ & & \\
$>30$ &
\end{tabular}

Values are median percentage [range].

controls [3.6\% (0.2-9.2) vs. 2.1\% (0.9-5.1), $P=0.04]$ (Fig. $1 B)$. Repeated blood samples were obtained after 7 days for 22 patients and after 3 mo for 25 patients. Circulating fibrocytes remained elevated at day 7 [3.7\% (0.6-7.1)] and after $3 \mathrm{mo}[3.4 \%$ (1.4-6.4)] with no significant difference as compared with the first sample (Fig. 1B).

Fibrocyte count was higher in samples collected more than 10 days after symptom onset compared with samples collected before 10 days after symptom onset [4.1\% (1.39.2), $n=33$ vs. $3.1 \%(0.2-8.0), n=24$, respectively; $P=$ 0.008] (Fig. 1C).

Among the hospitalized patients, the percentage of fibrocytes at admission was lower in the six patients who eventually died compared with survivors $[1.6 \%(0.2-4.4)$ vs. $3.7 \%$ (0.6-9.2), $P=0.02$ ] (Fig. 2). We found no significant difference in circulating fibrocyte count according to older or younger age, increased or normal body mass index (BMI), and male or female gender; all characteristics that have been reported as clinical risk factors for an unfavorable outcome in patients with COVID-19 pneumonia (Table 2). A significant positive correlation existed between blood monocyte and blood fibrocyte counts $(r=0.43, P=0.001)$. Conversely, no correlation existed between circulating fibrocyte count and biological markers associated with COVID-19 pneumonia severity, such as blood lymphocyte counts and LDH, CRP, D-dimer, or ferritin serum levels (Fig. 3).

Circulating fibrocyte count was lower in the 38 patients receiving corticosteroids before blood sampling compared with the 19 patients not receiving corticosteroids [3.2\% (0.2$8.6)$ vs. $4.5 \%$ (2.1-9.2), $P=0.002]$. In the treated group, corticosteroids were started 3.5 (1-26) days before blood sampling (Fig. 4A). These patients were more severe, as evidenced by higher oxygen requirement (median oxygen flow of $6 \mathrm{~L} / \mathrm{min}$ compared with $2 \mathrm{~L} / \mathrm{min}$ in patients who were not treated with corticosteroids at the time of sampling). Among these 38 patients, the percentage of circulating fibrocytes was significantly decreased in deceased patients $[1.34 \%(0.2-3.2)$, $n=5]$ as compared with survivors [3.44\% $(0.64-8.6), n=33$, $P=0.04]$ (Fig. $4 B$ ). In addition, blood fibrocyte count was negatively correlated with oxygen flow in hospitalized patients $(r=-0.34, P=0.02$ ) (Fig. $4 C$ ). A trend for a lower fibrocyte count was observed when the extension of COVID19 pneumonia on CT scan was $>75 \%$ [0.9\% $(0.2-3.4), n=4]$ compared with other groups [ $<25 \%: 3.7 \%(0.6-9.2), n=23$; 25\%-50\%: $4.1 \%$ (1.4-8.7), $n=22$; and 50\%-75\%: $3.6 \%(1.4-$ 6.3), $n=8 ; p=0.07$ ] (Fig. $4 D$ ).
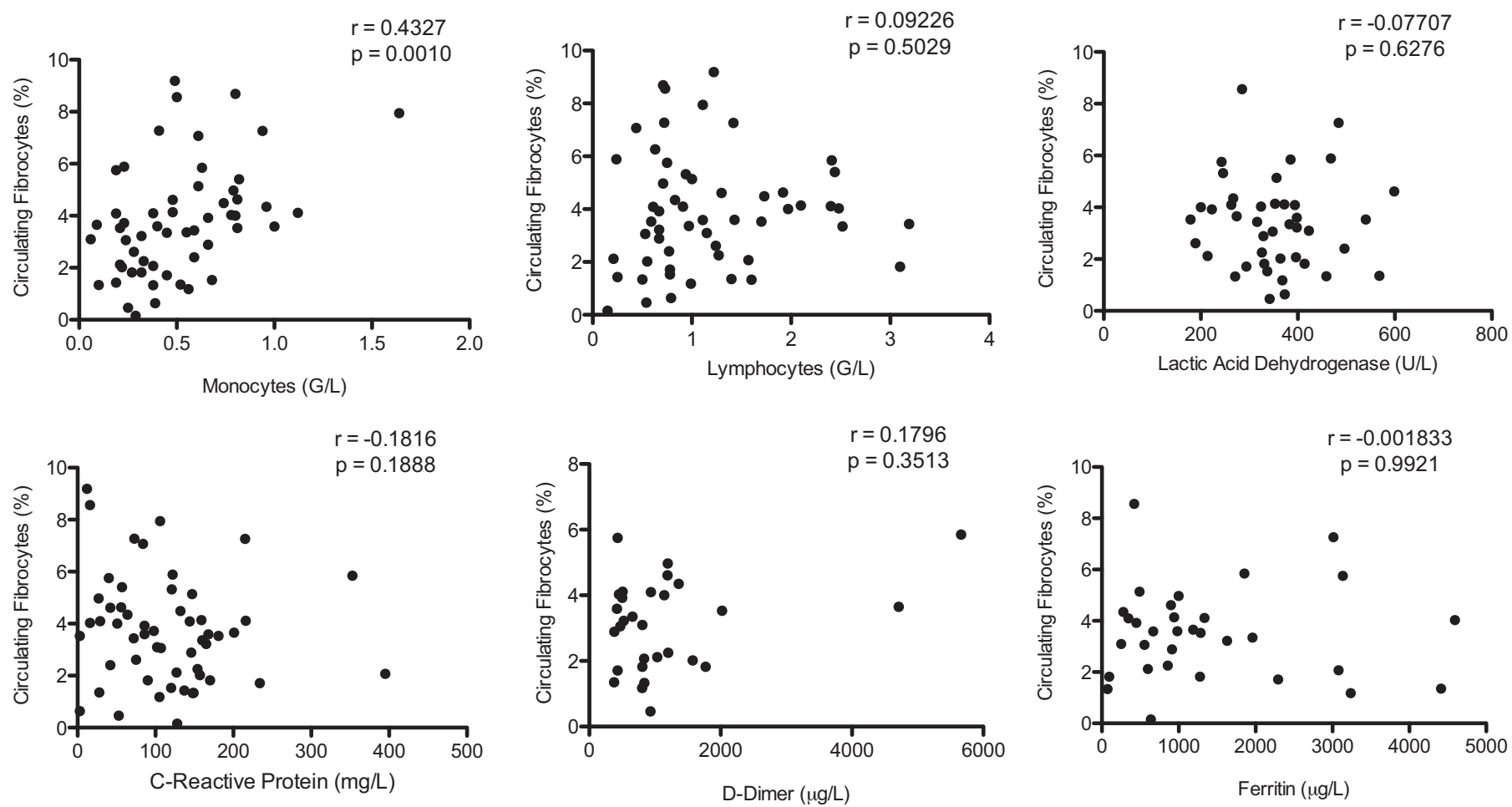

Figure 3. Circulating fibrocyte count was positively correlated with blood monocyte count but was not correlated to biological markers associated with COVID-19 severity [lymphocyte count, lactate dehydrogenase (LDH), C-reactive protein (CRP), D-dimer, and ferritin]. Spearman rank-order correlation coefficient. 
A

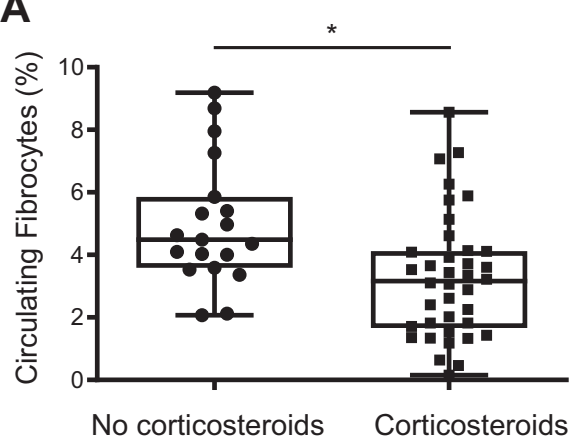

C

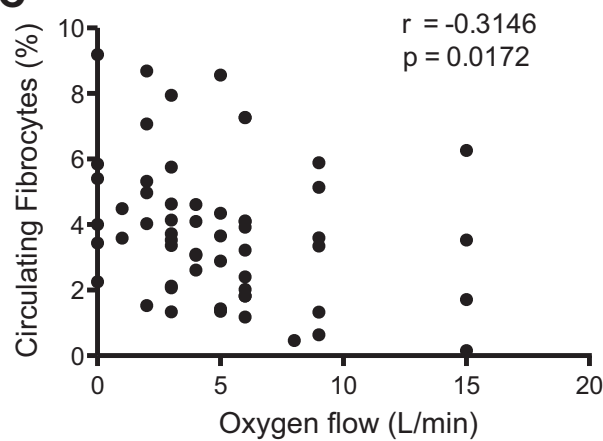

B

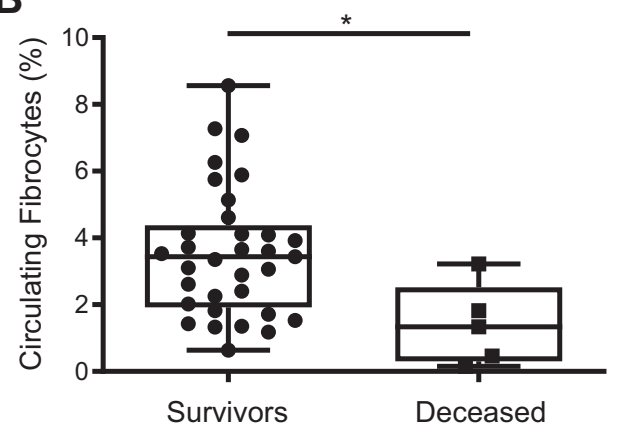

Among Patients under Corticosteroids

D

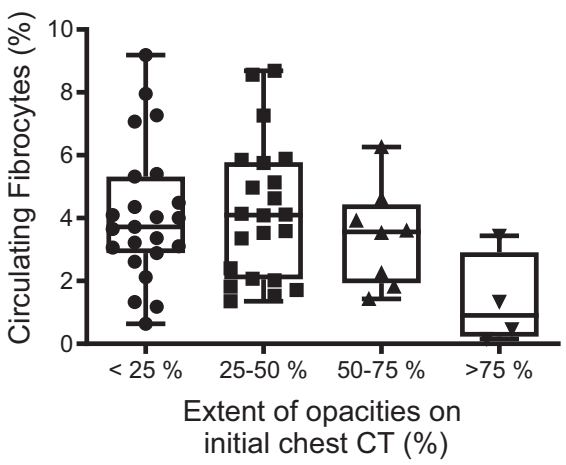

Figure 4. Circulating fibrocytes and severity. A: blood fibrocyte count was decreased in patients receiving corticosteroids for the treatment of COVID-19 before sample collection. Dot box-and-whisker plots with median showing the percentage of circulating fibrocytes among live mononuclear leukocytes in hospitalized patients treated with corticosteroids at the time of sampling $(n=38)$ and patients who were not treated $(n=19)$. Mann-Whitney $U$ test, * $P \leq 0.05$. B: blood fibrocyte count was lower in deceased patients as compared with survivors among hospitalized patients receiving corticosteroids for the treatment of COVID-19. Dot box-and-whisker plots with median showing the percentage of circulating fibrocytes among live mononuclear leukocytes in hospitalized patients treated with corticosteroids at the time of sampling (survivors, $n=33$; deceased, $n=5$ ). Mann-Whitney $U$ test, $* P \leq 0.05$. $C$ : blood fibrocyte count was negatively correlated with oxygen flow in hospitalized patients with COVID-19. Spearman rank-order correlation coefficient. $D$ : blood fibrocyte count was decreased when extension of pneumonia on computed tomography (CT) scan was $>75 \%$. Dot box-and-whisker plots with median showing the percentage of circulating fibrocytes among live mononuclear leukocytes according to the extension of the lesions on CT scan $(<25 \%: n=$ 23; $25 \%-50 \%: n=22 ; 50 \%-75 \%: n=8$; and $>75 \%: n=4)$. Kruskal-Wallis test, $P=0.07$.

\section{Blood and BAL Fibrocytes in ICU Patients}

A bronchoalveolar lavage was performed for a clinical suspicion of ventilator-associated pneumonia in seven out of the 13 patients of the ICU group, allowing to analyze fibrocyte counts in BAL and blood on the same day. Microbiological analysis was negative for all BAL samples. Circulating fibrocyte count was strongly decreased in patients from the ICU group compared with healthy controls and patients from the hospitalized group [0.8\% $(0.1-2.0)$ vs. $2.1 \%(0.9-5.1)$ and $3.6 \%(0.2-9.2)$, respectively, $P<0.001$ for both comparisons). BAL fibrocyte count was $6.7 \%$ (2.2-15.4) (Fig. 5).

\section{Association between Initial Circulating Fibrocyte Count and Patient Lung Course after 3 Mo of Follow-Up}

Thirty-two patients were evaluated 3 mo after the initial admission. A complete resolution of CT scan abnormalities was observed in 13 patients (40\%), in whom initial fibrocyte count was higher than in patients who experienced an incomplete lung damage resolution [4.5\% (0.6-7.3) vs. $3.4 \%$ (2.1-9.2), $P=0.04$ ] (Fig. 6).

\section{Serum Concentration of Modulators of Fibrocyte Recruitment and Differentiation}

CXCL12 is the main chemokine involved in the recruitment of fibrocytes to circulation and to the site of injury (28, 29). CCL2 and FGF2 have also been described to enhance the recruitment of fibrocytes after an injury $(30,31)$. We measured CXCL12, CCL2, and FGF2 concentrations in serum of patients with COVID-19 from the hospitalized and ICU groups ( $n=54 / 57$ and 7/13, respectively) and in serum of healthy controls $(n=12 / 16)$. Serum FGF2 concentration was below the detection level in all samples. Concentration of CXCL12 was increased in ICU patients [389.1 pg/mL (228.11053.0)] as compared with the hospitalized group [242.4 pg/ $\mathrm{mL}(137.6-1056)]$ and healthy controls $[210.5 \mathrm{pg} / \mathrm{mL}(138.7-$ 280.1); $P=0.0006$ ], whereas no difference was found between the hospitalized group and controls (Fig. 7A). Similar results were observed for CCL2 levels, with a higher concentration observed in ICU patients $[228.8 \mathrm{pg} / \mathrm{mL}(55.8-$ $485.2)]$ compared with the hospitalized group $[51.6 \mathrm{pg} / \mathrm{mL}$ (3.4-2388.0)] and healthy controls [40.6 pg/mL (15.3-158.6); $P=0.005]$, whereas no difference was found between the 


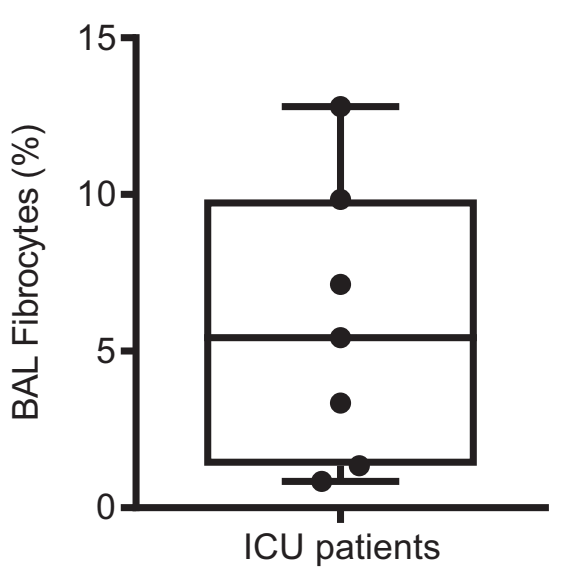

Figure 5. Percentage of fibrocytes in bronchoalveolar lavage (BAL) from patients with COVID-19 hospitalized in an intensive care unit (ICU). Dot boxand-whisker plots with median showing the percentage of fibrocytes among live mononuclear leukocytes in BAL of COVID-19 ICU patients $(n=7)$.

hospitalized group and controls (Fig. 7C). Circulating fibrocyte count was negatively correlated with serum CXCL12 and CCL2 concentrations in hospitalized and ICU patients (respectively, $r=-0.2364, P=0.046$, and $r=-0.3704, P=$ 0.003 ) (Fig. 7, $B$ and $C$ ).

SAP is the most potent inhibitor of fibrocyte differentiation $(32,33)$. In patients with ARDS, SAP has been demonstrated to inhibit monocyte-to-fibrocyte differentiation in BALF (27), whereas TGF- $\beta 1$ has been shown to induce monocyte-to-fibrocyte differentiation $(18,19,34)$. To better understand the mechanisms involved in fibrocyte differentiation during COVID-19 pneumonia, we measured serum SAP and TGF- $\beta 1$ levels in patients from the hospitalized and ICU groups and in healthy controls. Serum TGF- $\beta 1$ concentration was higher in the hospitalized group [333.3 pg/mL (3.41869.0)] as compared with healthy controls $[16.3 \mathrm{pg} / \mathrm{mL}$ (2.52-142.6); $P=0.0005$ ] (Fig. 7E). Serum SAP concentration was higher in patients from the hospitalized group [96.6 $\mu \mathrm{g} /$ $\mathrm{mL}(31.2-211.5), n=54]$ and the ICU group [119.7 $\mu \mathrm{g} / \mathrm{mL}(15.9-$ $153.2), n=7]$ compared with healthy controls $[65.0 \mu \mathrm{g} / \mathrm{mL}$ (40.4-118.1), $n=16 ; P=0.0046]$. Serum SAP concentration was not statistically different between the ICU group and the hospitalized group (Fig. $7 G$ ). There was no correlation between serum TGF- $\beta 1$ or SAP concentrations and circulating fibrocyte count (Fig. 7, $F$ and $H$ ).

\section{Evidence for Fibrocyte Accumulation in the Lung during COVID-19 Pneumonia}

Immunofluorescence staining was performed on human lung sections obtained from two patients with COVID-19. Patient 1 developed symptomatic COVID-19 pneumonia 2 days after bullous emphysema surgery; RT-PCR was positive for SARS-Cov-2 on the lung sample obtained during surgery. Patient 2 underwent lung cancer surgery 4 wk after first symptoms of COVID-19 pneumonia. We used lung samples obtained during surgery to detect fibrocytes, defined as CD45 and vimentin double-positive spindle-shaped cells, by immunofluorescence, according to Kasam et al. (35). We were able to identify fibrocytes in both samples (Fig. 8), suggesting that fibrocytes are present in the lung tissue in the early phase (patient 1) and the late phase (patient 2) of COVID-19 pneumonia.

\section{DISCUSSION}

To our knowledge, this is the first study reporting circulating and alveolar fibrocyte counts during moderate-to-severe COVID-19 pneumonia. Our data indicate that 1) in patients hospitalized in a conventional ward for COVID-19 pneumonia, circulating fibrocyte counts were increased compared with healthy controls; 2) circulating fibrocyte counts were higher in surviving patients and in patients with better lung repair at 3 mo as assessed by CT scan; 3) circulating fibrocyte counts were markedly decreased in ICU patients compared with healthy controls and patients hospitalized for a less severe COVID-19 pneumonia; and 4) fibrocytes were detected in BALF in ICU patients and in lung samples obtained from patients with COVID-19.

In this study, we found a significantly higher circulating fibrocyte count in patients suffering from moderate-tosevere COVID-19 pneumonia requiring hospitalization in conventional wards compared with healthy controls. Blood fibrocytes have been shown to increase in many different pathological conditions with tissue injury (36). Changes in circulating fibrocyte counts during infectious pneumonia are poorly described. In one study, patients admitted to the ICU with severe infectious pneumonia but without ARDS showed higher circulating fibrocyte counts than controls (21). In a murine model of Klebsiella pneumoniae-induced lung infection, fibrocyte count increased in the bone marrow, the blood, and the lung compartments (21). Fibrocytes are recruited to the lung in a model of $\gamma$-herpes virus infection in mice, and this recruitment depended in part on the activation of the CCR2 receptor by CCL2 and CCL12 (37).

Fibrocytes are recruited from the bone marrow through the bloodstream to the target tissues, mainly by the CXCR4CXCL12 axis $(28,29)$. Other chemokine ligand-receptor axes

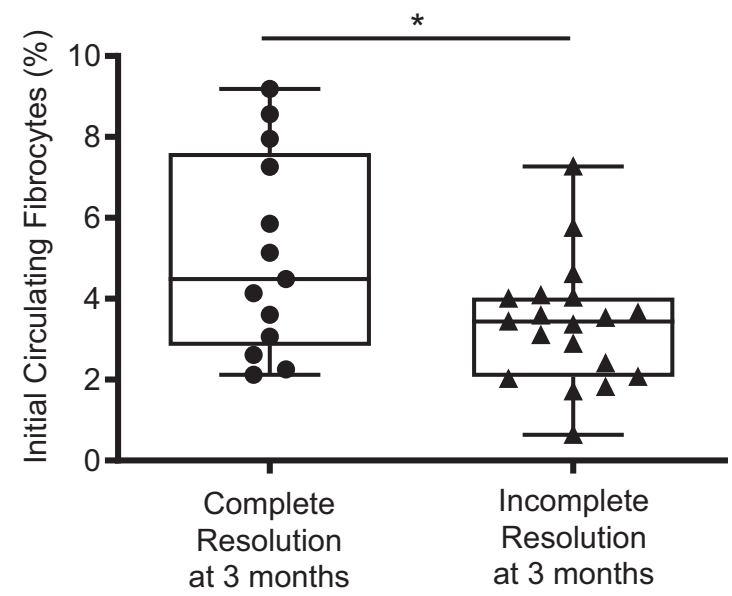

Figure 6. A higher initial circulating fibrocyte count was associated with a complete computed tomography $(\mathrm{CT})$ resolution after 3-mo follow-up. Dot box-and-whisker plots with median showing the percentage of circulating fibrocytes among live mononuclear leukocytes in healthy controls $(n=16)$, patients with COVID-19 showing a complete CT resolution $(n=13)$, and patients with COVID-19 showing an incomplete CT resolution $(n=19)$. Mann-Whitney $U$ test, $* P \leq 0.05$. 
Figure 7. Serum concentration of cytokines involved in fibrocyte recruitment and differentiation. $A$ : CXCL12 concentration was significantly increased in intensive care unit (ICU) patients as compared with hospitalized patients and healthy controls. Dot box-andwhisker plots with median range showing the concentration of CXCL12 in healthy controls $(n=12)$, hospitalized patients $(n=54)$, and ICU patients $(n=7)$. Kruskal-Wallis test, $P=0.0006$. B: CXCL12 concentration was negatively correlated with circulating fibrocytes count in hospitalized and ICU patients. CXCL12 concentration and percentage of circulating fibrocytes were measured in blood of hospitalized $(n=54)$ and ICU patients $(n=7)$. Spearman rank-order correlation coefficient. C: CCL2 concentration was increased in ICU patients as compared with hospitalized patients and healthy controls. Dot box-and-whisker plots with median range showing the concentration of CCL2 in healthy controls $(n=12)$, hospitalized patients $(n=54)$, and ICU patients ( $n=$ 7). Kruskal-Wallis test, $P=0.0053 . D$ : CCL2 concentration was negatively correlated with circulating fibrocyte count in hospitalized and ICU patients. CCL2 concentration and percentage of circulating fibrocytes were measured in blood of hospitalized patients $(n=54)$ and ICU patients $(n=7)$. Spearman rank-order correlation coefficient. $E$ : TGF- $\beta 1$ concentration was increased in hospitalized patients with COVID-19 as compared with healthy controls. Dot box-andwhisker plots with median range showing the concentration of TGF- $\beta 1$ in healthy controls $(n=12)$, hospitalized patients $(n=54)$, and ICU patients $(n=7)$. Kruskal-Wallis test, $P=0.0005$. $F$ : no correlation was found between TGF- $\beta 1$ concentration in serum and circulating fibrocyte count in hospitalized and ICU patients. TGF- $\beta 1$ concentration and percentage of circulating fibrocytes were measured in blood of hospitalized $(n=$ 54 ) and ICU patients $(n=7)$. Spearman rankorder correlation coefficient. $G$ : serum amyloid protein (SAP) concentration was increased in hospitalized patients with COVID-19 as compared with healthy controls. Dot box-and-whisker plots with median range showing the concentration of SAP in healthy controls $(n=12)$, hospitalized patients $(n=54)$, and ICU patients $(n=7)$. Kruskal-Wallis test, $P=0.046$. $\mathrm{H}$ : no correlation was found between SAP concentration and circulating fibrocyte count in hospitalized and ICU patients. SAP concentration and percentage of circulating fibrocytes were measured in blood of hospitalized $(n=54)$ and ICU patients $(n=7)$. Spearman rank-order correlation coefficient. $* P<0.05$; $* * P<$ $0.01 ; * * * P<0.001$.
A

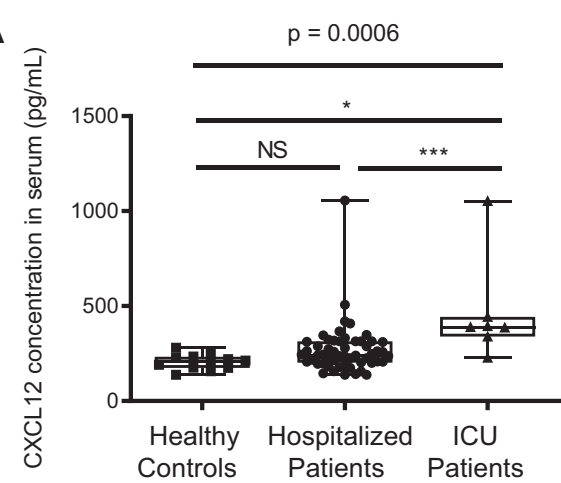

C

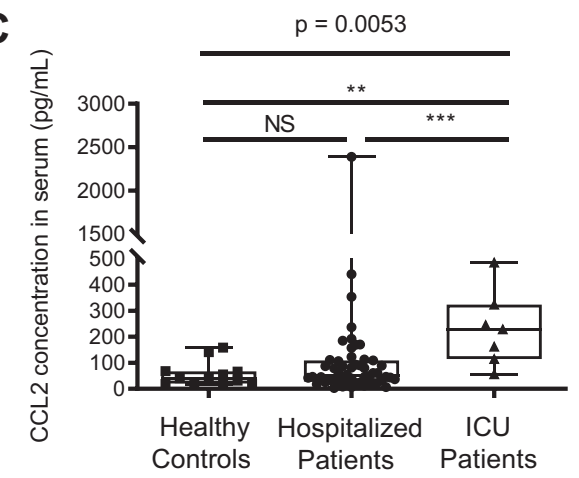

$E$

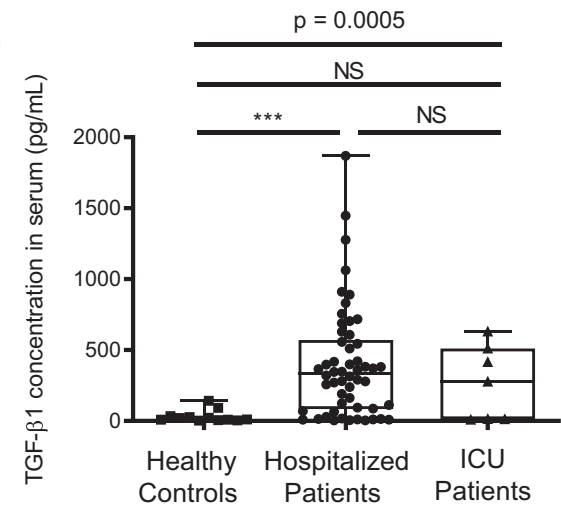

G

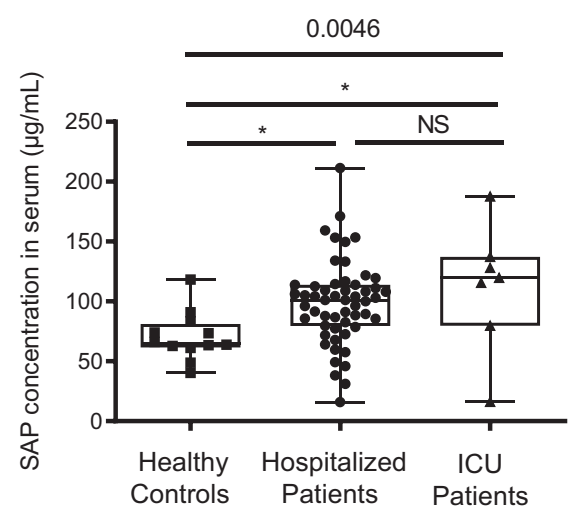

B

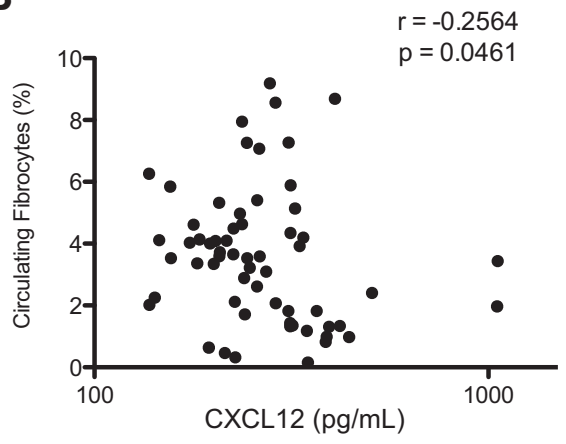

D

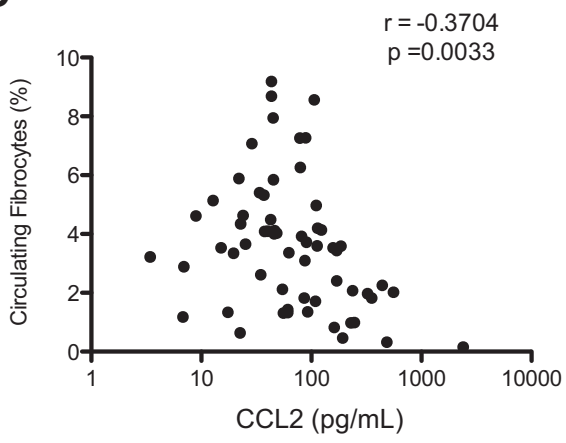

$\mathbf{F}$

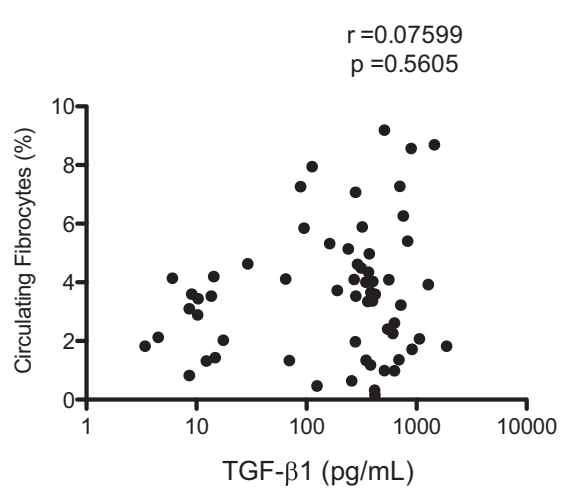

H

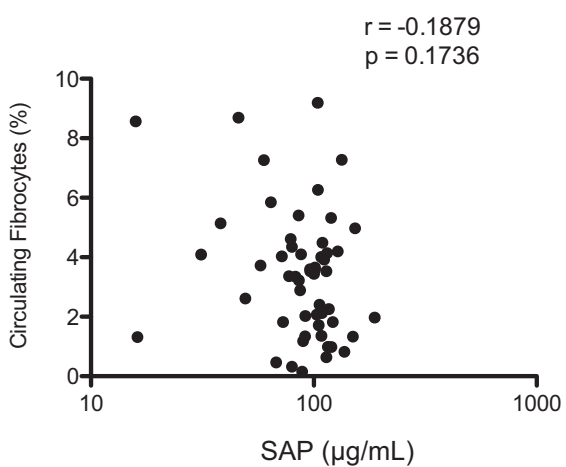

are involved in fibrocyte recruitment, including CCR2-CCL2, CCR2-CCL12, and CCR7-CCL21 (31). We observed that serum CXCL12 and CCL2 concentrations were increased in patients with COVID-19. An increased expression of CXCL12 in the lung during COVID-19 pneumonia has been reported (38, 39). Similarly, an overexpression of CCL2 in BALF (40), in macrophages of the upper and lower respiratory tracts of patients with severe COVID-19 (41), and in BAL monocyte- 
Patient 1

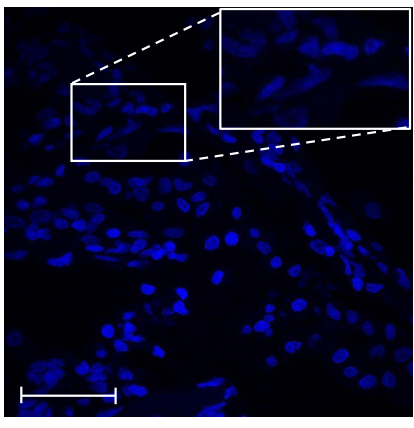

DAPI

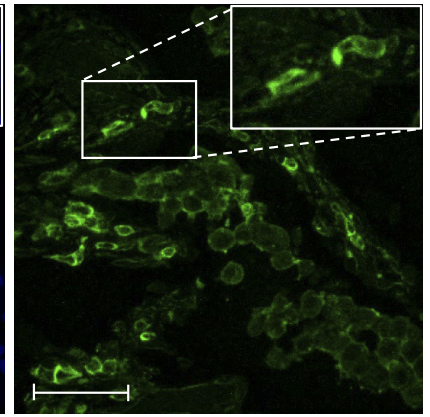

CD45

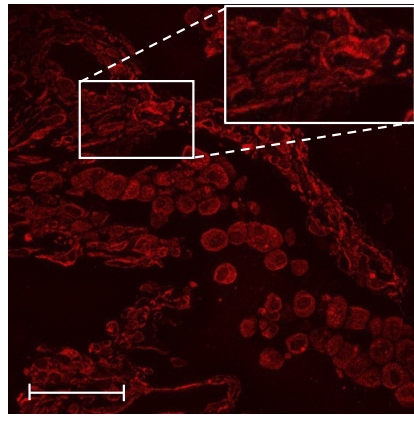

Vimentin

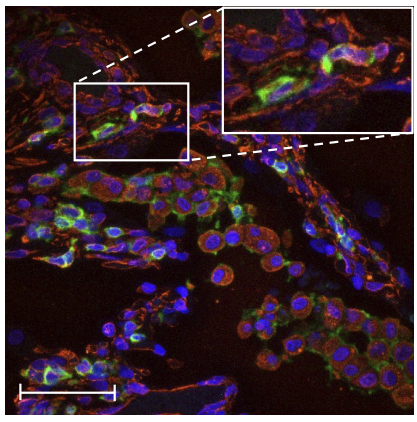

Merge

Patient 2

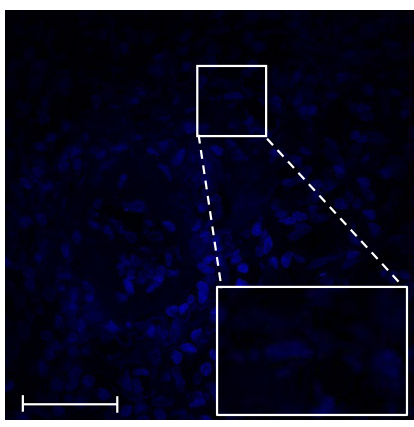

DAPI

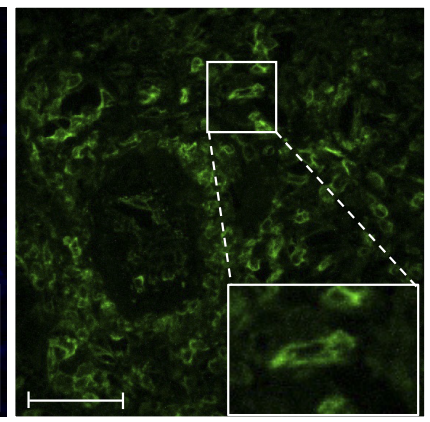

CD45

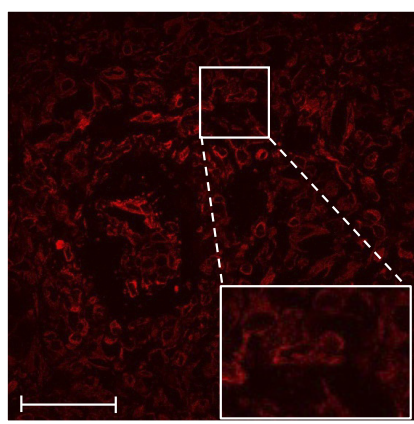

Vimentin

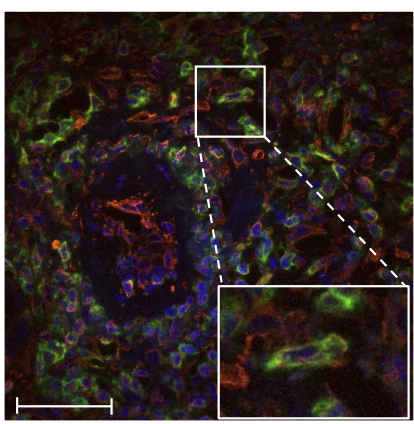

Merge

Figure 8. Detection of fibrocytes in COVID-19 lung samples using hematopoietic (CD45) and mesenchymal markers (vimentin) by fluorescence microscopy. Frozen lung sections from patients with COVID-19 were co-immunostained using CD45 and vimentin. DAPI was used for nuclei staining. Arrows indicate CD45 and vimentin double-positive cells. Scale bar: $50 \mu \mathrm{m}$. Patient 1 developed symptomatic COVID-19 pneumonia 2 days after bullous emphysema surgery, with RT-PCR positive for COVID-19 on the lung sample. Patient 2 underwent lung cancer surgery 4 wk after first symptoms of COVID-19 pneumonia.

derived macrophages of patients with severe COVID-19 (12) has been described. Surprisingly, serum CXCL12 and CCL2 concentrations negatively correlated with blood fibrocyte count, with lower concentrations being associated with a higher circulating fibrocyte count. However, the lung is the main source of CXCL12 and CCL2 during acute lung injury $(42,43)$, and we suspect that lung concentrations of CXCL12 and CCL2 were much higher, thereby promoting the recruitment of fibrocyte from the circulation to the lung. Unfortunately, BAL supernatant was not available to compare CXCL12 and CCL2 concentrations in those patients.

More surprisingly, circulating fibrocyte count was hugely decreased in ICU patients critically affected by COVID-19 as well as in deceased hospitalized patients.

We and others have described an increase of blood and BAL fibrocytes during ARDS $(21,22)$. This increase was associated with poorer outcomes and higher mortality $(21,22)$. Blood fibrocytes result from a complex balance between the differentiation of monocyte to fibrocyte, the transition of fibrocytes from bone marrow to circulation, and the recruitment of fibrocytes from circulation to the site of injury (36). We observed that serum concentration of TGF- $\beta 1$, an enhancer of monocyte-to-fibrocyte differentiation, was increased in hospitalized patients but not in ICU patients, whereas levels of SAP, a potent inhibitor of monocyte-tofibrocyte differentiation, were increased in the two groups of patients (hospitalized and ICU). These data support an imbalance toward an inhibition of monocyte-to-fibrocyte differentiation in ICU patients, which could contribute to the very low level of blood fibrocytes observed in ICU patients. Interestingly, Schulte-Schrepping et al. (44) showed that a defective monocyte activation was a characteristic of patients with severe COVID-19, whereas an early activation of monocytes with a strong antiviral IFN signature was a hallmark of mild COVID-19. Finally, these mechanisms are being influenced by therapeutics, since corticosteroids have been shown to inhibit monocyte-tofibrocyte differentiation (27).

The measurement of circulating fibrocytes was repeated in a subgroup of patients and we observed a persistent elevation of fibrocyte counts over those measured in healthy subjects. Lin et al. (21) previously reported that circulating fibrocytes displayed intermittent episodes of marked elevation in patients with ARDS evaluated serially over their ICU stay. However, this is the first report of a sustained increase of circulating fibrocytes several months after the initial lung injury. Further studies are needed to determine if this is specific of COVID-19 and which mechanisms are at the origin of such a prolonged increase. 
Long-term persistence of post-COVID-19 pulmonary lung damages, including fibrosis, is being increasingly recognized. In a recent study, fibrotic-like changes (including bronchiectasis, parenchymal bands, and/or honeycombing) were observed in 35\% patients (40/114) 6 mo after their COVID-19 pneumonia (45). Multivariate analysis identified age $>50 \mathrm{yr}$, heart rate $>100$ beats $/ \mathrm{min}$, hospital length of stay $\geq 17$ days, noninvasive mechanical ventilation, and a large extent of the opacities on the initial CT scan as independent predictors of fibrotic-like changes at 6 mo. Our results suggest that the initial circulating fibrocyte count could be predictive of the evolution of CT scan abnormalities after a 3-mo follow-up. Indeed, patients in whom a complete resolution of parenchymal opacities was observed had higher initial count of circulating fibrocytes. Further investigations are required to determine the underlying mechanisms. However, the recruitment of fibrocytes to the blood and then to the injured tissue is part of the normal woundhealing process $(16,46-49)$. This may contribute to explain, at least in part, the relation between higher fibrocyte counts and better outcomes, both in terms of survival and effective lung repair.

Our study has some limitations. First, this is a single-center study that included a relatively small number of patients. Our results deserve to be confirmed in larger studies. Second, we had access to a limited number of BALF samples, only from ICU patients, since bronchoscopy was not routinely performed in patients with COVID-19 to limit the risk of transmission to healthcare workers and was reserved for intubated patients in the ICU with a clinical suspicion of hospital-acquired pneumonia. Thus, determining the potential relation between blood and alveolar fibrocyte counts at the individual level will require complementary studies.

In conclusion, our results provide new data contributing to a better understanding of the role of fibrocytes during COVID-19 pneumonia. Additional studies are needed to confirm the prognostic value of circulating fibrocytes during COVID-19 and to understand their role in lung repair after COVID-19 pneumonia.

\section{ACKNOWLEDGMENTS}

We thank the patients and families, and all medical and paramedical teams from Bichat Hospital. We thank Gregory Gautier (Inserm 1149) for help in flow cytometry and Nicolas Heddebaut (Inserm 1152) for help in luminex assay. We thank all investigators for the French COVID cohort study group, including the following: Alpha Diallo, Christelle Paul, Noémie Mercier, Soizic Le Mestre, Ventzislava Petrov-Sanchez (ANRS, Paris, France), Claire Andrejak ( $\mathrm{CHU}$ Amiens, France), Catherine Chirouze (CHU Jean Minjoz, Besançon, France), Denis Malvy (CHU Bordeaux, France), Dominique Deplanque, François Dubos (CHU Lille, France), Patrick Rossignol (CHU Nancy, France), Manuel Etienne (CHU Rouen, France), Bénédicte Rossignol, Claire Levy-Marchal, Morgane Gilg, Tristan Gigante (FCRIN INI-CRCT, Paris, France), Beluze Marine (F-CRIN Partners Platform, Paris, France), JeanSebastien Hulot (Hôpital Européen Georges Pompidou, Paris, France), Anissa Chair, Antoine Khalil, Benoit Visseaux, Camille Couffignal, Carine Roy, Cédric Laouénan, Charlene DA Silveira, Coralie Tardivon, Delphine Bachelet, Diane Descamps, France Mentré, François Bompart, François-Xavier Lescure, Gilles Peytavin, Isabelle Gorenne, Isabelle Hoffmann, Jade Ghosn, Jean christophe Lucet, Jean-François Timsit, Jimmy Mullaert, Krishna Bhavsar, Lila
Bouadma, Lysa Tagherset, Marie- Capucine Tellier, Marie-Pierre Debray, Marina Esposito-Farese, Marion Schneider, Minh Le, Nadia Ettalhaoui, Nas- sima Si Mohammed, Nathalie Gault, Nathan PeifferSmadja, Ouifiya Kefif, Philippine Eloy, Quentin Le Hingrat, Sabrina Kali, Samira Laribi, Sarah Tubiana, Théo Trioux, Xavier Duval, Yazdan Yazdanpanah (Hôpital Bichat, Paris, France), Noémie Vanel (hôpital la timone, Marseille, France), Olivier Picone, Romain Basmaci (Hôpital Louis Mourier, Colombes, France), François Angoulvant (Hôpital Necker, Paris, France), Florentia Kaguelidou, Justine Pages (Hôpital Robert Debré, Paris, France), Aurélie Veislinger, Christelle Tual (Inserm CIC-1414, Rennes, France), Aurélie Papado-Poulos, Hélène Esperou, Salma Jaafoura, Sandrine CouffinCadiergues (Inserm sponsor, Paris, France), Alexandra Coelho, Alexandre Hoctin, Alphonsine Diouf, Marina Mambert (Inserm UMR 1018, Paris, France), Alexandre Gaymard, Bruno Lina, Manuel RosaCalatrava, Maude Bouscambert, Olivier Terrier (Inserm UMR 1111, Lyon, France), Amina Meziane, Céline Dorival, Dehbia Benkerou, François Téoulé (Inserm UMR 1136, Paris, France), Guillaume Lingas, Hervé Le Nagard, Jérémie Guedj, Nadège Neant (Inserm UMR 1137, Paris, France), Laurent Abel (Inserm UMR 1163, Paris, France), Coralie Khan, Mathilde Desvallée (Inserm UMR 1219, Bordeaux, France), Aurélie Wiedemann, Yves Levy (Inserm UMR 955, Créteil, France), Hugo Mouquet, Sylvie Behilill, Sylvie van der Werf, Vincent Enouf (Pasteur Institute, Paris, France), Caroline Semaille, Eric d'OR-Tenzio, Minerva Cervantes-Gonzalez, Oriane Puéchal (RE-ACTing, Paris, France), and Marion Noret (RENARCl, Annecy, France).

\section{GRANTS}

This work was supported by the Agence Nationale de la Recherche (ANR) (FIBROCO AAP RA-COVID-19 V12) and by project INFLAMEX (ANR-10-LABX-17). M. Ghanem was supported by Inserm ("Poste d'Accueil 2020"), and M. Homps-Legrand was supported by Fond de dotation "Recherche en Santé Respiratoire" (Grant 2018).

\section{DISCLOSURES}

B. Crestani is the principal investigator of the NINTECOR trial (NCT04541680) (Nintedanib for the Treatment of SARS-Cov-2 Induced Pulmonary Fibrosis). None of the other authors has any conflicts of interest, financial or otherwise, to disclose.

\section{AUTHOR CONTRIBUTIONS}

M. Ghanem, M.H.L., L.d.C., M.J., A.M., C.N., R.B., M.H.N., B.C., and T.F. conceived and designed research; M. Ghanem, M.J., A.M., N.P., and M.H.L. performed experiments; M. Ghanem, M.J., A.M., N.P., M.P.D., M.H.L., B.C., and M. Garnier analyzed data; M. Ghanem, M.J., A.M., N.P., M.H.L., B.C., and M. Garnier interpreted results of experiments; M. Ghanem, M.H.L., and B.C. prepared figures; M. Ghanem, B.C., and M. Garnier drafted manuscript; M. Ghanem, M.H.L., L.d.C., M.J., A.M., C.Q., M.P.D., E.d.M., C.N., R.B., M.H.N., C.T., B.C., T.F., M. Garnier, L.M., T.G., J.F.M., P.H.W., P.J., and C.B. edited and revised manuscript; M. Ghanem, M.H.L., L.d.C., M.J., A.M., C.Q., N.P., M.P.D., E.d.M., C.N., R.B., M.H.N., C.T., B.C., T.F., M. Garnier, L.M., T.G., J.F.M., P.H.W., P.J., and C.B. approved final version of manuscript.

\section{REFERENCES}

Huang C, Wang Y, Li X, Ren L, Zhao J, Hu Y, Zhang L, Fan G, Xu J, Gu X, Cheng Z, Yu T, Xia J, Wei Y, Wu W, Xie X, Yin W, Li H, Liu M, Xiao Y, Gao H, Guo L, Xie J, Wang G, Jiang R, Gao Z, Jin Q, Wang J, Cao B. Clinical features of patients infected with 2019 novel 
coronavirus in Wuhan, China. Lancet 395: 497-506, 2020. doi:10.1016/S0140-6736(20)30183-5.

2. Elezkurtaj S, Greuel S, Ihlow J, Michaelis EG, Bischoff P, Kunze 16 CA, Sinn BV, Gerhold M, Hauptmann K, Ingold-Heppner B, Miller F, Herbst H, Corman VM, Martin H, Radbruch H, Heppner FL, 17 Horst D. Causes of death and comorbidities in hospitalized patients with COVID-19. Sci Rep 11: 4263, 2021. doi:10.1038/s41598-02182862-5.

3. Bourgonje AR, Abdulle AE, Timens W, Hillebrands J, Navis GJ, $>18$ Gordijn SJ, Bolling MC, Dijkstra G, Voors AA, Osterhaus AD, Voort PH, Mulder DJ, Goor H. Angiotensin-converting enzyme 2 (ACE2), SARS-COV-2 and the pathophysiology of coronavirus disease 2019 (COVID-19). J Pathol 251: 228-248, 2020. doi:10.1002/path.5471.

4. Hariri LP, North CM, Shih AR, Israel RA, Maley JH, Villalba JA Vinarsky V, Rubin J, Okin DA, Sclafani A, Alladina JW, Griffith JW, Gillette MA, Raz Y, Richards CJ, Wong AK, Ly A, Hung YP, Chivukula RR, Petri CR, Calhoun TF, Brenner LN, Hibbert KA, 20 . Medoff BD, Hardin CC, Stone JR, Mino-Kenudson M. Lung histopathology in coronavirus disease 2019 as compared with severe acute respiratory syndrome and H1N1 influenza: a systematic review. Chest 159: 73-84, 2021. doi:10.1016/j.chest.2020.09.259.

5. Fox SE, Akmatbekov A, Harbert JL, Li G, Brown JQ, Vander Heide RS. Pulmonary and cardiac pathology in Covid-19: the first autopsy series from New Orleans. medRxiv 2020.04.06.20050575, 2020. doi:10.1101/2020.04.06.20050575.

6. Xu Z, Shi L, Wang Y, Zhang J, Huang L, Zhang C, Liu S, Zhao P, Liu $>22$. H, Zhu L, Tai Y, Bai C, Gao T, Song J, Xia P, Dong J, Zhao J, Wang F-S. Pathological findings of COVID-19 associated with acute respiratory distress syndrome. Lancet Respir Med 8: 420-422, 2020 [Erratum in Lancet Respir Med 8: e26, 2020]. doi:10.1016/S22132600(20)30076-X.

7. Aesif SW, Bribriesco AC, Yadav R, Nugent SI Zubkus D, Tan CD, 23. Mehta AC, Mukhopadhyay S. Pulmonary pathology of COVID-19 following 8 weeks to 4 months of severe disease: a report of three cases, including one with bilateral lung transplantation. Am J Clin Pathol 155: 506-514, 2021. doi:10.1093/ajcp/aqaa264.

8. Zhou F, Yu T, Du R, Fan G, Liu Y, Liu Z, Xiang J, Wang Y, Song B, 24 . Gu X, Guan L, Wei Y, Li H, Wu X, Xu J, Tu S, Zhang Y, Chen H, Cao B. Clinical course and risk factors for mortality of adult inpatients with COVID-19 in Wuhan, China: a retrospective cohort study. The Lancet 395: 1054-1062, 2020. doi:10.1016/S0140-6736(20)30566-3. 25.

9. Williamson EJ, Walker AJ, Bhaskaran K, Bacon S, Bates C, Morton CE, Curtis HJ, Mehrkar A, Evans D, Inglesby P, Cockburn J, McDonald HI, MacKenna B, Tomlinson L, Douglas IJ, Rentsch CT, Mathur R, Wong AYS, Grieve R, Harrison D, Forbes H, Schultze A, Croker R, Parry J, Hester F, Harper S, Perera R, Evans SJW, Smeeth L, Goldacre B. Factors associated with COVID-19-related death using $\longrightarrow 26$. OpenSAFELY. Nature 584: 430-436, 2020. doi:10.1038/s41586-0202521-4.

10. Yan L, Zhang H-T, Goncalves J, Xiao Y, Wang M, Guo Y, Sun C, Tang $X$, Jing L, Zhang $M$, Huang $X$, Xiao $Y$, Cao H, Chen Y, Ren T, Wang F, Xiao Y, Huang S, Tan X, Huang N, Jiao B, Cheng C, Zhang Y, Luo A, Mombaerts L, Jin J, Cao Z, Li S, Xu H, Yuan Y. An inter- 27. pretable mortality prediction model for COVID-19 patients. Nat Mach Intel/ 2: 283-288, 2020. doi:10.1038/s42256-020-0180-7.

11. Liao M, Liu Y, Yuan J, Wen Y, Xu G, Zhao J, Cheng L, Li J, Wang X, Wang F, Liu L, Amit I, Zhang S, Zhang Z. Single-cell landscape of bronchoalveolar immune cells in patients with COVID-19. Nat Med 26: 842-844, 2020. doi:10.1038/s41591-020-0901-9.

12. Grant RA, Morales-Nebreda L, Markov NS, Swaminathan S, Querrey M, Guzman ER, Abbott DA et al. Circuits between infected macrophages and T cells in SARS-CoV-2 pneumonia. Nature 590: 635-641, 2021. doi:10.1038/s41586-020-03148-w.

13. Suga H, Rennert RC, Rodrigues M, Sorkin M, Glotzbach JP, Januszyk M, Fujiwara T, Longaker MT, Gurtner GC. Tracking the elusive fibrocyte: identification and characterization of collagen-producing hematopoietic lineage cells during murine wound healing. Stem Cells 32: 1347-1360, 2014. doi:10.1002/stem.1648.

14. Hinz B, Phan SH, Thannickal VJ, Prunotto M, Desmoulière A, Varga J, De Wever O, Mareel M, Gabbiani G. Recent developments in myofibroblast biology. Am J Pathol 180: 1340-1355, 2012. doi:10.1016/j.ajpath.2012.02.004.

15. Nakashima T, Liu T, Yu H, Ding L, Ullenbruch M, Hu B, Wu Z, Oguro H, Phan SH. Lung bone marrow-derived hematopoietic progenitor cells enhance pulmonary fibrosis. Am J Respir Crit Care Med 188: 976-984, 2013. doi:10.1164/rccm.201303-04790C.

Herzog EL, Bucala R. Fibrocytes in health and disease. Exp Hematol 38: 548-556, 2010. doi:10.1016/j.exphem.2010.03.004.

Dupin I, Contin-Bordes C, Berger P. Fibrocytes in asthma and chronic obstructive pulmonary disease: Variations on the same theme. Am J Respir Cell Mol Biol 58: 288-298, 2018. doi:10.1165/ rcmb.2017-0301PS.

Shao DD, Suresh R, Vakil V, Gomer RH, Pilling D. Pivotal advance: Th-1 cytokines inhibit, and Th-2 cytokines promote fibrocyte differentiation. J Leukoc Bio/ 83: 1323-1333, 2008. doi:10.1189/jlb.1107782.

Murray LA, Chen Q, Kramer MS, Hesson DP, Argentieri RL, Peng X, Gulati M, Homer RJ, Russell T, van Rooijen N, Elias JA, Hogaboam CM, Herzog EL. TGF-beta driven lung fibrosis is macrophage dependent and blocked by serum amyloid P. Int J Biochem Cell Bio/ 43: 154-162, 2011. doi:10.1016/j.biocel.2010.10.013.

Tai W, Zhou Z, Zheng B, Li J, Ding J, Wu H, Gao L, Dong Z. Inhibitory effect of circulating fibrocytes on injury repair in acute lung injury/acute respiratory distress syndrome mice model. J Cell Biochem 119: 7982-7990, 2018. doi:10.1002/jcb.26664.

Lin CM, Alrbiaan A, Odackal J, Zhang Z, Scindia Y, Sung S-SJ, Burdick MD, Mehrad B. Circulating fibrocytes traffic to the lung in murine acute lung injury and predict outcomes in human acute respiratory distress syndrome: a pilot study. Mol Med 26: 52, 2020. doi:10.1186/s10020-020-00176-0.

Quesnel C, Piednoir P, Gelly J, Nardelli L, Garnier M, Leçon V, Lasocki S, Bouadma L, Philip I, Elbim C, Mentré F, Soler P. Crestani B, Dehoux M. Alveolar fibrocyte percentage is an independent predictor of poor outcome in patients with acute lung injury. Crit Care Med 40: 21-28, 2012. doi:10.1097/CCM. Ob013e31822d718b.

Moeller A, Gilpin SE, Ask K, Cox G, Cook D, Gauldie J, Margetts PJ, Farkas L, Dobranowski J, Boylan C, O'Byrne PM, Strieter RM, Kolb M. Circulating fibrocytes are an indicator of poor prognosis in idiopathic pulmonary fibrosis. Am J Respir Crit Care Med 179: 588-594, 2009. doi:10.1164/rccm.200810-15340C.

Borie R, Quesnel C, Phin S, Debray M-P, Marchal-Somme J, Tiev K, Bonay M, Fabre A, Soler P, Dehoux M, Crestani B. Detection of alveolar fibrocytes in idiopathic pulmonary fibrosis and systemic sclerosis. PLoS One 8: e53736, 2013. doi:10.1371/journal.pone.0053736.

Heukels P, van Hulst JAC, van Nimwegen M, Boorsma CE, Melgert BN, van den Toorn LM, Boomars KAT, Wijsenbeek MS, Hoogsteden H, von der Thüsen JH, Hendriks RW, Kool M, van den Blink B. Fibrocytes are increased in lung and peripheral blood of patients with idiopathic pulmonary fibrosis. Respir Res 19: 90, 2018. doi:10.1186/s12931-018-0798-8.

Debray M-P, Tarabay H, Males L, Chalhoub N, Mahdjoub E, Pavlovsky T, Visseaux B, Bouzid D, Borie R, Wackenheim C, Crestani B, Rioux C, Saker L, Choquet C, Mullaert J, Khalil A. Observer agreement and clinical significance of chest CT reporting in patients suspected of COVID-19. Eur Radio/ 31: 1081-1089, 2021. doi:10.1007/s00330-020-07126-8.

Garnier M, Mailleux AA, Besnard V, Abback PS, Leçon V, Neuville M, Gouel A, Crestani B, Dehoux M, Quesnel C. Serum amyloid P contained in alveolar fluid from patients with acute respiratory distress syndrome mediates the inhibition of monocyte differentiation into fibrocyte. Crit Care Med 44: e563-e573, 2016. doi:10.1097/ CCM.0000000000001612.

28. Phillips RJ, Burdick MD, Hong K, Lutz MA, Murray LA, Xue YY, Belperio JA, Keane MP, Strieter RM. Circulating fibrocytes traffic to the lungs in response to CXCL12 and mediate fibrosis. J Clin Invest 114: 438-446, 2004. doi:10.1172/JCl200420997.

29. Andersson CK, Andersson-Sjöland A, Mori M, Hallgren O, Pardo A, Eriksson L, Bjermer L, Löfdahl C-G, Selman M, WestergrenThorsson G, Erjefält JS. Activated MCTC mast cells infiltrate diseased lung areas in cystic fibrosis and idiopathic pulmonary fibrosis. Respir Res 12: 139, 2011. doi:10.1186/1465-9921-12-139.

30. Moore BB, Kolodsick JE, Thannickal VJ, Cooke K, Moore TA, Hogaboam C, Wilke CA, Toews GB. CCR2-mediated recruitment of fibrocytes to the alveolar space after fibrotic injury. Am J Pathol 166: 675-684, 2005. doi:10.1016/S0002-9440(10)62289-4.

Gurczynski SJ, Procario MC, O'Dwyer DN, Wilke CA, Moore BB. Loss of CCR2 signaling alters leukocyte recruitment and exacerbates $\gamma$-herpesvirus-induced pneumonitis and fibrosis following 
bone marrow transplantation. Am J Physiol Lung Cell Mol Physiol 311: L611-L627, 2016. doi:10.1152/ajplung.00193.2016.

32. Pilling D, Buckley CD, Salmon M, Gomer RH. Inhibition of fibrocyte 41 . differentiation by serum amyloid P. J Immunol Baltim Immunol 171: 5537-5546, 2003. doi:10.4049/jimmunol.171.10.5537.

-33. Naik-Mathuria B, Pilling D, Crawford JR, Gay AN, Smith CW Gomer RH, Olutoye OO. Serum amyloid P inhibits dermal wound healing. Wound Repair Regen 16: 266-273, 2008. doi:10.1111/j.1524475X.2008.00366.X.

-34. Abe R, Donnelly SC, Peng T, Bucala R, Metz CN. Peripheral blood fibrocytes: Differentiation pathway and migration to wound sites. J Immunol 166: 7556-7562, 2001. doi:10.4049/jimmunol. 166.12.7556.

35. Kasam RK, Gajjala PR, Jegga AG, Courtney JA, Randell SH, Kramer EL, Clancy JP, Madala SK. Fibrocyte accumulation in the lungs of cystic fibrosis patients. J Cyst Fibros Off J bros 19: 815-822, 2020. doi:10.1016/j.jcf.2020.06.011.

36. Chong SG, Sato S, Kolb M, Gauldie J. Fibrocytes and fibroblastswhere are we now. Int J Biochem Cell Biol 116: 105595, 2019. doi:10.1016/j.biocel.2019.105595.

37. McMillan TR, Moore BB, Weinberg JB, Vannella KM, Fields WB Christensen PJ, van Dyk LF, Toews GB. Exacerbation of established pulmonary fibrosis in a murine model by gammaherpesvirus. Am J Respir Crit Care Med 177: 771-780, 2008. doi:10.1164/ rccm.200708-11840C.

38. Ackermann M, Mentzer SJ, Kolb M, Jonigk D. Inflammation and intussusceptive angiogenesis in COVID-19: everything in and out of flow. Eur Respir J 56, 2020. doi:10.1183/13993003.03147-2020.

39. Leng L, Cao R, Ma J, Mou D, Zhu Y, Li W, Lv L, Gao D, Zhang S, 47 Gong F, Zhao L, Qiu B, Xiang H, Hu Z, Feng Y, Dai Y, Zhao J, Wu Z, Li H, Zhong W. Pathological features of COVID-19-associated lung injury: a preliminary proteomics report based on clinical samples Signal Transduct Target Ther 5: 240, 2020. doi:10.1038/s41392020-00355-9.

-40. Xiong Y, Liu Y, Cao L, Wang D, Guo M, Jiang A, Guo D, Hu W, Yang J, Tang Z, Wu H, Lin Y, Zhang M, Zhang Q, Shi M, Liu Y, Zhou Y, Lan K, Chen Y. Transcriptomic characteristics of bronchoalveolar lavage fluid and peripheral blood mononuclear cells in COVID-19 patients. Emerg Microbes Infect 9: 761-770, 2020. doi:10.1080/ 22221751.2020.1747363.

Chua RL, Lukassen S, Trump S, Hennig BP, Wendisch D, Pott F et al. COVID-19 severity correlates with airway epithelium-immune cell interactions identified by single-cell analysis. Nat Biotechnol 38: 970-979, 2020. doi:10.1038/s41587-020-0602-4.

42. Petty JM, Sueblinvong V, Lenox CC, Jones CC, Cosgrove GP, Cool CD, Rai PR, Brown KK, Weiss DJ, Poynter ME, Suratt BT. Pulmonary stromal-derived factor-1 expression and effect on neutrophil recruitment during acute lung injury. J Immunol Baltim Immunol 178: 8148-8157, 2007. doi:10.4049/jimmunol.178.12. 8148.

43. Bhatia M, Zemans RL, Jeyaseelan S. Role of chemokines in the pathogenesis of acute lung injury. Am J Respir Cell Mol Biol 46: 566-572, 2012. doi:10.1165/rcmb.2011-0392TR.

44. Schulte-Schrepping J, Reusch N, Paclik D, Baßler K, Schlickeiser S, Zhang B et al. Severe COVID-19 is marked by a dysregulated myeloid cell compartment. Cell 182: 1419-1440, 2020. e23 doi:10.1016/j. cell.2020.08.001.

45. Han X, Fan Y, Alwalid O, Li N, Jia X, Yuan M, Li Y, Cao Y, Gu J, Wu H, Shi H. Six-month follow-up chest CT findings after severe COVID-19 pneumonia. Radiology 299: E177-E186, 2021. doi:10. 1148/radiol.2021203153.

46. Mehrad B, Burdick MD, Zisman DA, Keane MP, Belperio JA Strieter RM. Circulating peripheral blood fibrocytes in human fibrotic interstitial lung disease. Biochem Biophys Res Commun 353: 104108, 2007. doi:10.1016/j.bbrc.2006.11.149.

Bellini A, Mattoli S. The role of the fibrocyte, a bone marrow-derived mesenchymal progenitor, in reactive and reparative fibroses. $L a b$ Invest 87: 858-870, 2007. doi:10.1038/labinvest.3700654.

48. Mori L, Bellini A, Stacey MA, Schmidt M, Mattoli S. Fibrocytes contribute to the myofibroblast population in wounded skin and originate from the bone marrow. Exp Cell Res 304: 81-90, 2005. doi:10.1016/j.yexcr.2004.11.011.

Bianchetti L, Barczyk M, Cardoso J, Schmidt M, Bellini A, Mattoli S. Extracellular matrix remodelling properties of human fibrocytes. J Cell Mol Med 16: 483-495, 2012. doi:10.1111/j.1582-4934.2011.01344.x. 